\title{
Associations between primary health care strategies and outcomes of mental disorders
}

\author{
Leonardo Moscovici, ${ }^{1}$ iD Estenifer M. Balco, ${ }^{1}$ Natalia C. Degani, ${ }^{1}$ Lívia M. Bolsoni, ${ }^{2}$ \\ João M.A. Marques, ${ }^{1}$ Antonio W. Zuardi ${ }^{2}$ \\ ${ }^{1}$ Departamento de Medicina Social, Faculdade de Medicina de Ribeirão Preto (FMRP), Universidade de São Paulo (USP), Ribeirão Preto, SP, \\ Brazil. ${ }^{2}$ Departamento de Neurociências e Ciências do Comportamento, FMRP, USP, Ribeirão Preto, SP, Brazil. \\ This study was presented as a poster at the 22nd WONCA World Conference, in Seoul, Korea, October 17-21, 2018.
}

\begin{abstract}
Objective: To investigate associations between the percentage and severity of mental disorders (MD) and three different primary health care (PHC) strategies in Brazil: traditional care (TC), the Family Health Strategy (FHS), and FHS with shared mental health care (FHS + SC).

Methods: Random samples were selected from three different areas of a Brazilian city. Each area was served by a different PHC strategy (TC, FHS, or FHS + SC). Five mental health professionals, blinded to the type of PHC strategy delivered in each area, conducted interviews using the Mini International Neuropsychiatric Interview (MINI) and other specific instruments to assess the prevalence and severity of MD.

Results: 530 subjects were interviewed. The TC strategy was significantly associated with a higher percentage of MD when compared to FHS and FHS + SC. These results were not affected by adjustment for sociodemographic variables. The difference in prevalence of MD between the two FHS areas (with and without SC) was not statistically significant. No significant differences in MD severity were observed across the three PHC strategies.

Conclusion: Areas covered by FHS showed a lower percentage of MD than those covered by TC. Presence of SC did not influence the prevalence of MD, suggesting that mental-health training of FHS teams may have minimized the influence of SC.
\end{abstract}

Keywords: Primary health care; mental health; collaborative care; family health strategy

\section{Introduction}

Primary health care $(\mathrm{PHC})$ is the backbone of publicly funded health systems in many countries. It is the first level of care, dealing with roughly $90 \%$ of all health issues. After the Declaration of Alma-Ata in 1978, PHC started to play a major role worldwide, from low- to highincome countries. In this context, assessments of the effects of strategies to improve primary care are essential for health promotion. ${ }^{1}$

Brazil, a middle-income country, has since 1988 relied upon a universal health system, known in Portuguese as the Sistema Único de Saúde (SUS), or Unified Health System. In Brazil, PHC is delivered either by traditional care (TC), at units staffed by internal medicine specialists, pediatricians, gynecologists, nurses, and nurse technicians, or via Family Health Strategy (FHS) teams. The FHS is a specific community-based PHC approach implemented in 1994. Each FHS team - which includes one family physician or general practitioner, one nurse, one nurse technician, and four to six community health workers covers an area of 1,000 households (or a population of up to 4,000). Currently, 125 million Brazilians are under the care of FHS teams, which corresponds to approximately $65 \%$ of the country's population. ${ }^{2,3}$

PHC should serve as the gateway for detection and early management of mental disorders (MD). ${ }^{4}$ Neuropsychiatric disorders are among the leading causes of nonfatal disability, and approximately $9.5 \%$ of all years of life lost to disability in Brazil are caused by MD. ${ }^{5}$ Worldwide, about $50 \%$ of patients with MD are not followed up by health services, a proportion that is even higher in low- and middle-income countries. ${ }^{6}$

The detection and management of MD by PHC teams are still quite unsatisfactory. ${ }^{6}$ Several studies have shown that intense, personalized, and continuous contact between $\mathrm{PHC}$ and mental health teams improves the detection and follow-up of MD by PHC teams. ${ }^{4,7-12}$ This approach has been described as collaborative, integrated, or shared care (SC) and, in Brazil, was given the name matrix support. Such interventions are usually characterized by ensuring personalized patient follow-up by the same PHC provider across treatments; training of the PHC team in interview techniques, diagnostic tools,
Correspondence: Leonardo Moscovici, Av. dos Bandeirantes, 3900, CEP 14048-900, Ribeirão Preto, SP, Brazil.

E-mail: leoscovici@gmail.com

Submitted Aug 16 2019, accepted Dec 12 2019, Epub Apr 032020.
How to cite this article: Moscovici L, Balco EM, Degani NC, Bolsoni LM, Marques JMA, Zuardi AW. Associations between primary health care strategies and outcomes of mental disorders. Braz J Psychiatry. 2020;42:360-366. http://dx.doi.org/10.1590/1516-4446-2019-0659 
and pharmacological and psychotherapeutic guidelines; stable consultancy over time by the same mental health professionals, with discussion of cases and issues with the PHC team; and availability of channels for prompt contact between mental-health and PHC team providers, facilitating prompt decision making.

This strategy of care has shown beneficial effects for patients with MD. ${ }^{4,7-14}$ Because of the great diversity of interventions defined as SC, collaborative care, or matrix support, it is important to assess the effectiveness of each strategy. In Brazil, the SC model - when present - is most often integrated with the work of FHS teams.

We hypothesized that populations in areas assisted by FHS teams would have better MD outcomes than those covered by TC, and that SC would further improve FHS performance. The aim of the current study was to compare mental health outcomes from patients whose care was delivered according to each of the following three strategies: FHS teams staffed by family physicians alone, without mental health SC (defined as the FHS group); FHS teams staffed by family physicians with SC support (FHS + SC), and TC (provided by PHC teams without family physicians).

\section{Method}

\section{Context and setting}

The study was conducted in Ribeirão Preto, in the state of São Paulo, Brazil, from May to December 2013. Ribeirão Preto is a medium-sized city with a metropolitan population of nearly 1.5 million. ${ }^{15}$ Three areas of the city were selected according to the type of health care delivered, all of which were linked to the Faculdade de Medicina de Ribeirão Preto (FMRP), Universidade de São Paulo. Each of the three areas was served by a different health care strategy: TC, FHS, or FHS + SC.

At the time of the study, SC was provided by mental health specialists (including a senior psychiatrist), who visited the staff and provided specialized support on a weekly basis. During these visits, the mental health professionals spent most of their time delivering mental health support to the PHC teams, rather than having direct contact with patients. Telephone and e-mail contact were also used to assist FHS teams.

All four family physicians (two from the FHS area and two from the FHS + SC area) had received mental health training during their 1-year medical residency in Family and Community Medicine, which consisted of 80 hours of theoretical seminars on mental health in PHC, 300 hours of practical training in a psychiatric emergency service, and participation in weekly shared mental health care meetings (which included consultations in the PHC setting).

\section{Sample}

This article refers to Phase 2 of a large cross-sectional study. Phase 1 , described in a previous publication, ${ }^{15}$ involved 1,545 subjects randomly selected on the basis of a household geographical information system covering the three areas (FHS, FHS + SC, and TC) ${ }^{16} \mathrm{~A}$ random sample - involving $50 \%$ of Phase 1 participants - was contacted and invited to participate in Phase 2.

All patients who agreed to participate signed an informed consent form. Patients with cognitive impairment were excluded.

\section{Instruments}

- Mini International Neuropsychiatric Interview (MINI), a semi-structured interview for DSM-IV axis I specific diagnoses, with good validity indices. ${ }^{17-19}$

- MINI-Tracking, an instrument validated in Portuguese that is very similar to the MINI, with the exception that it offers a five-degree scale of severity instead of yes and no answers. ${ }^{20}$

- Patient Health Questionnaire-9 (PHQ-9), a nine-item tool that evaluates the severity of depression, with good psychometric characteristics. ${ }^{20-22}$

- Generalized Anxiety Disorder Scale-7 (GAD-7), a sevenitem instrument that assesses the severity of anxiety. ${ }^{23,24}$

- Alcohol Use Disorder Identification Test (AUDIT), translated into Brazilian Portuguese and validated for use in Brazil. 25,26

- Brief Psychiatric Rating Scale (BPRS), validated Brazilian Portuguese version, to assess psychotic symptoms. ${ }^{27}$

\section{Procedures}

Subjects were contacted by phone. Those who agreed to participate in this new phase of the study were visited by a health professional for a diagnostic interview and assessment of symptom severity (only for patients with MD). Five mental health professionals (four psychologists and one occupational therapist) were trained in the use of the instruments and received a schedule of visits with equal numbers of residents in the three study areas. These mental health professionals were not aware of the type of health care strategy delivered to the residents in the area.

Subjects were first interviewed for diagnostic assessment with the MINI. Then, to assess the severity of symptoms in patients with positive diagnoses, the MINITracking was applied. Depending on the diagnoses, the following instruments were also administered: PHQ-9 (depression), GAD-7 (anxiety), AUDIT (alcohol abuse/ dependence), and BPRS (psychotic symptoms).

Once all interviews had been completed, one of the psychologists visited all health units of the study in order to identify, by going through the subjects' health records, those who had actually received care at the respective unit (not necessarily mental health care or SC) in the preceding 12 months. This assessment was necessary because the sample has been randomized by household, and only a percentage of participants had received direct care from $\mathrm{PHC}$ teams in the last year.

\section{Data analysis}

We used the chi-square test to compare the sex of participants and the frequency of MD diagnosed among 
Table 1 Sex distribution of participants across the three study areas

\begin{tabular}{lccccc}
\hline & $\begin{array}{c}\text { FHS }+ \text { SC } \\
(n=208)\end{array}$ & $\begin{array}{c}\text { FHS } \\
(n=156)\end{array}$ & $\begin{array}{c}\text { TC } \\
(n=174)\end{array}$ & Chi-square & 1.539 \\
\hline Male & 76 & 67 & 68 & 0.463 \\
Female & 132 & 89 & 106 & \\
\hline
\end{tabular}

FHS = Family Health Strategy; FHS + SC = FHS with shared mental health care; TC = traditional care.

the participants who received any care from a PHC team and those who did not receive care over the last year in the three areas.

The influences of study areas and sociodemographic variables (sex, age, education, marital status, employment status, and socioeconomic level) on the occurrence of $\mathrm{MD}$ were assessed with univariate binary logistic regression analysis. Variables with $p<0.05$ or between 0.06 and 0.10 were interpreted as significant or having borderline statistical significance, respectively. They were then included in a multiple logistic regression model with adjusted odds ratios (OR). Results are reported as unadjusted (crude) and adjusted ORs, with a 95\% confidence interval $(95 \% \mathrm{Cl})$.

To evaluate the influence of area of residence on the severity of diagnosed MD according to the type of health care delivered, MD diagnoses were grouped into four categories: depressive disorders (major depressive episode and dysthymia), anxiety disorders (panic disorder, agoraphobia, social anxiety disorder, post-traumatic stress disorder, and obsessive-compulsive disorder), alcohol abuse/dependence, and psychotic syndromes. The severity of symptoms was measured on the basis of mean MINI-Tracking scores and, depending on the diagnosis, on the scores of the specific instrument(s) described in the Procedures section. These data were analyzed by analysis of variance (ANOVA). 20.0 .

All statistical analyses were performed in SPSS version

\section{Ethics statement}

The study was approved by the research ethics committee of the FMRP University Hospital (process HCRP 13325/2012). All patients signed an informed consent for prior to their inclusion in the study.

\section{Results}

We randomly selected 773 subjects for the study, of whom 538 agreed to participate (a response rate of approximately $70 \%$ ). Differences in gender and age were not significant. Table 1 shows the distribution of participants by sex across the three areas of the study, which was also statistically homogeneous. As shown in Table 2, the MINI disclosed a high percentage of depressive and anxiety disorders in the sample, as well as comorbidity (co-occurrence of more than one MD).

Table 3 shows the frequencies of MD diagnoses established with the MINI and their associations with different variables: area of residence, sex, age, educational attainment, marital status, employment status,
Table 2 Percentage of mental disorders across all three areas

\begin{tabular}{lc}
\hline Diagnosis: category/disorder & \\
\hline Anxiety disorders & $22(4.1)$ \\
Panic & $39(7.2)$ \\
Agoraphobia & $12(2.2)$ \\
Social anxiety & $2(0.4)$ \\
Post-traumatic stress & $92(17.1)$ \\
Generalized anxiety & $16(3.0)$ \\
Obsessive-compulsive & $144(27.2)$ \\
Any anxiety disorder & \\
& \\
Depressive disorders & $133(24.7)$ \\
Major depressive episode & $29(5.4)$ \\
Dysthymia & $157(29.2)$ \\
Any depressive disorder & $56(10.4)$ \\
Bipolar disorder I and II & \\
Substance abuse/dependence & $19(3.5)$ \\
Alcohol & $14(2.6)$ \\
Other drugs & $30(5.6)$ \\
$\quad$ Any abuse/dependence & \\
Psychotic syndrome & $41(7.6)$ \\
Any psychotic syndrome & $218(40.5)$ \\
\hline Any* mental disorder & \\
\hline Data presented as $\mathrm{n}$ (\%). & \\
* The sum of the frequencies of the individual diagnoses differs from \\
the frequency of any mental disorder because of diagnostic \\
comorbidity.
\end{tabular}

and socioeconomic status. Logistic regression analysis showed an association between area of residence and frequency of MD diagnoses, with a higher frequency in the area covered by the TC unit compared to areas served by FHS. This association was significant for both crude and adjusted ORs, taking into account variables with significant associations (sex, educational attainment, and marital status). There were no differences in MD prevalence between FHS areas with vs. without SC.

Figure 1 shows that, among participants who did not have any care delivered by PHC teams over the previous year, there were no significant differences in the frequency of MD diagnosed with the MINI. However, in those seen by a PHC team in the preceding year, the frequency of MD was significantly higher among participants in the TC group (chi-square $=7.23, \mathrm{p}=$ $0.027)$. In this group, the difference between patients who actually received care by the $\mathrm{PHC}$ team $(29 \%)$ and those who did not receive care was statistically significant (chisquare $=7.02, p=0.008$ ). Patients who did receive care in the FHS + SC (40.9\%) and FHS (39\%) groups did not differ from those who did not receive care. 
Table 3 Frequency of MINI diagnoses and results of logistic regression

\begin{tabular}{|c|c|c|c|c|}
\hline \multirow[b]{2}{*}{ Variables } & \multicolumn{2}{|c|}{ Mental disorder, n (\%) } & \multirow[b]{2}{*}{$\begin{array}{l}\text { Crude OR }(95 \% \mathrm{Cl}) \\
\text { [p-value] }\end{array}$} & \multirow[b]{2}{*}{$\begin{array}{c}\text { Adjusted OR* }(95 \% \mathrm{Cl}) \\
{[\mathrm{p} \text {-value] }}\end{array}$} \\
\hline & Negative MINI & Positive MINI & & \\
\hline \multicolumn{5}{|l|}{ Area (TC vs. FHS and $\mathrm{FHS}+\mathrm{SC}$ ) } \\
\hline $\mathrm{TC}$ & $90(51.7)$ & $84(48.3)$ & $\begin{array}{c}1.602(1.111-2.309) \\
{[p=0.012]}\end{array}$ & $\begin{array}{c}1.523(1.046-2.218) \\
{[p=0.028]}\end{array}$ \\
\hline $\mathrm{FHS}$ and $\mathrm{FHS}+\mathrm{SC}$ & $230(63.2)$ & $134(36.8)$ & & \\
\hline \multicolumn{5}{|l|}{ Area (FHS vs. FHS + SC) } \\
\hline $\mathrm{FHS}+\mathrm{SC}$ & $135(64.9)$ & $73(35.1)$ & $\begin{array}{c}1.187(0.773-1.825) \\
{[p=0.433]}\end{array}$ & - \\
\hline FHS & $95(60.9)$ & $61(39.1)$ & & \\
\hline \multicolumn{5}{|l|}{ Sex } \\
\hline Male & $141(66.8)$ & $70(32.2)$ & $\begin{array}{c}1.665(1.162-2.384) \\
{[p=0.005]}\end{array}$ & $\begin{array}{c}1.823(1.251-2.656) \\
{[p=0.002]}\end{array}$ \\
\hline Female & $179(54.7)$ & $148(45.3)$ & & \\
\hline Age (years), median & 50 & 49 & $\begin{array}{c}0.993(0.984-1.002) \\
{[p=0.141]}\end{array}$ & \\
\hline \multicolumn{5}{|l|}{ Educational attainment } \\
\hline Primary education incomplete & $87(58.8)$ & $61(41.2)$ & $\begin{array}{c}1.543(0.868-2.741) \\
{[p=0.140]}\end{array}$ & $\begin{array}{c}1.603(0.879-2,922) \\
{[p=0.124]}\end{array}$ \\
\hline Primary education complete & $55(53.4)$ & $48(46.6)$ & $\begin{array}{c}1.920(1.042-3.537) \\
{[p=0.035]}\end{array}$ & $\begin{array}{c}2.045(1.092-3.830) \\
{[p=0.025]}\end{array}$ \\
\hline Secondary education complete & $123(59.4)$ & $84(40.6)$ & $\begin{array}{c}1.502(0.868-2.599) \\
{[p=0.146]}\end{array}$ & $\begin{array}{c}1.491(0.849-2.618) \\
{[p=0.164]}\end{array}$ \\
\hline Higher education complete & $55(68.8)$ & $25(31.2)$ & - & \\
\hline \multicolumn{5}{|l|}{ Marital status } \\
\hline Married/cohabitating & $206(63.4)$ & $119(36.6)$ & - & - \\
\hline Single & $58(49.2)$ & $60(50.8)$ & $\begin{array}{c}1.791(1.170-2.741) \\
{[p=0.007]}\end{array}$ & $\begin{array}{c}1.829(1.180-2.836) \\
{[p=0.007]}\end{array}$ \\
\hline Divorced/widowed & $54(58.7)$ & $38(41.3)$ & $\begin{array}{c}1.218(0.760-1.954) \\
{[p=0.413]}\end{array}$ & $\begin{array}{c}1.022(0.618-1.689) \\
{[p=0.933]}\end{array}$ \\
\hline \multicolumn{5}{|l|}{ Employment status } \\
\hline Employed/self-employed & $166(58.5)$ & $118(41.5)$ & & - \\
\hline Housewife/student & $53(60.9)$ & $34(39.1)$ & $\begin{array}{c}0.902(0.552-1.475) \\
{[p=0.68]}\end{array}$ & - \\
\hline Unemployed & 100 (60.2) & $66(38.8)$ & $\begin{array}{c}0.928(0.628-1.372) \\
{[p=0.709]}\end{array}$ & \\
\hline \multicolumn{5}{|l|}{ Socioeconomic class } \\
\hline $\mathrm{D} / \mathrm{E}$ & $16(55.2)$ & $13(44.8)$ & $\begin{array}{c}1.271(0.588-2.748) \\
{[p=0.541]}\end{array}$ & \\
\hline C & 135 (58.2) & 97 (41.8) & $\begin{array}{c}1.124(0.788-1.604) \\
{[p=0.518]}\end{array}$ & \\
\hline$A / B$ & $169(61.0)$ & $108(39.0)$ & - & - \\
\hline
\end{tabular}

$95 \% \mathrm{Cl}=95 \%$ confidence interval; FHS = Family Health Strategy (FHS); MINI = International Neuropsychiatric Interview; OR = odds ratio; $\mathrm{SC}=$ shared care; $\mathrm{TC}=$ traditional care units.

Socioeconomic class defined according to the Brazilian Market Research Association Economic Classification Criteria (Critério Brasil).

To evaluate the influence of area of residence according to the type of health coverage delivered on the severity of diagnosed MDs, the four diagnostic categories described above (depressive disorders, anxiety disorders, alcohol abuse/dependence, and psychotic syndromes) were compared. The ANOVA of these results is presented in Table 4. No significant differences were observed between the three areas, although there was a trend toward significant differences in severity in MINI-Tracking scores in the depressive disorders category. Due to this finding, data from the two areas covered by FHS and from the area covered by TC were compared. This revealed a trend toward greater severity in the area covered by TC $($ mean $=1.54$ vs. 1.78 , Student's $t=1.86$; $p=0.06$ ). Comparison between the two areas covered by FHS teams, with and without SC, did not reveal a significant difference (Student's $t=1.08 ; \mathrm{p}=0.28$ ).

\section{Discussion}

We assessed the influence of different PHC models on MD outcomes in three areas of a Brazilian city and found the following frequencies of MD diagnoses with the MINI interview: $48.3 \%$ in the area covered by TC, $35.1 \%$ in the area covered by FHS with SC, and $39.1 \%$ in the area covered by FHS alone (without SC). To investigate associations between $\mathrm{PHC}$ strategies and other variables that could influence the percentage of MD, all data obtained 
were subjected to a logistic regression analysis. This analysis showed a statistically significant difference in the percentage of MD between the area where care was delivered by the TC strategy and the two areas covered by FHS. The significant difference persisted even after the analysis was adjusted by sociodemographic variables, which also showed significant differences (in sex, educational attainment, and marital status of participants). Conversely, the difference in the percentage of MD between the two FHS areas (with and without SC) did not reach statistical significance. These findings are in line with those from a previous study performed in the same

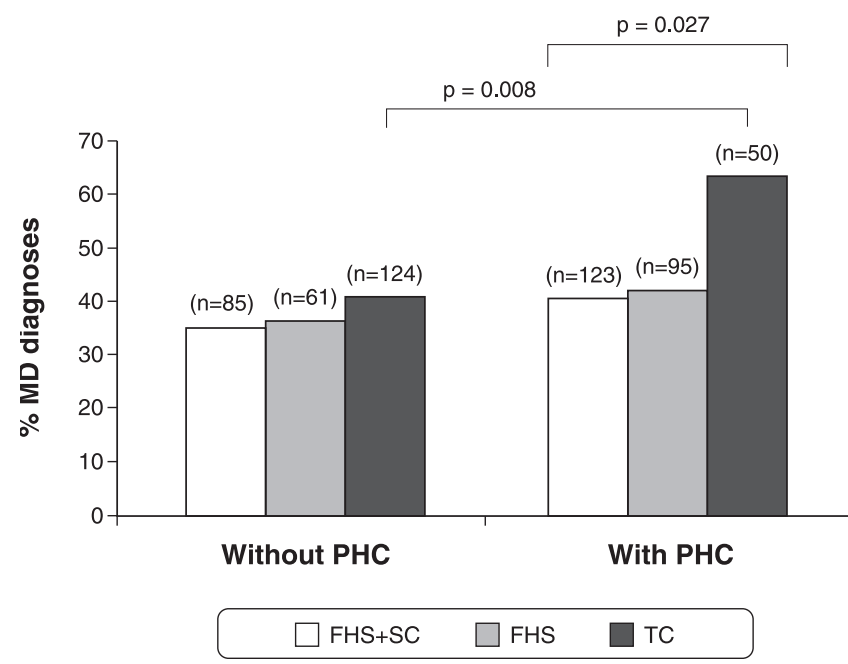

Figure 1 Comparison of the percentage of MD diagnoses between participants who did not receive any $\mathrm{PHC}$ intervention in the 12 months preceding study enrollment and those who had care delivered by one of the three PHC strategies: FHS with shared mental health care (FHS + SC), FHS alone, or TC. FHS = Family Health Strategy; $\mathrm{MD}=$ mental disorders; $\mathrm{PHC}=$ primary health care; $\mathrm{TC}=$ traditional care. areas, with a larger number of participants, and with MD identified using a screening instrument. ${ }^{15}$

The higher frequency of MD diagnoses in participants who reside in the area covered by TC could be due to other variables that were not controlled for in this study. However, we consider this possibility unlikely, since participants that did not receive any care from the PHC teams exhibited a similar prevalence of MINI-detected MD in all three areas (Figure 1); only those who had received $\mathrm{PHC}$ showed a higher frequency of MD diagnoses in the TC group. Patients with MD may require more from PHC teams; however, those covered by FHS who received care showed the same frequency of MD as those who did not receive any care, and the frequency of MD was higher only among those covered by TC. It is possible that the TC strategy is failing to detect and adequately treat MDs, which would be consistent with the existing literature. ${ }^{6}$ In the FHS, family physicians and their teams are able to offer adequate care and support for emotional suffering, which probably reduces the prevalence of MD. This suggests that TC is less effective than a family physician-led strategy (FHS) in managing MD.

In the samples of this study, the SC model did not influence the frequency of $M D$ diagnoses, since no significant differences were found between the FHS and FHS + SC groups. The most recent literature does not support this finding. Instead, consistent observation points to the beneficial effects of SC on the outcomes of patients with MD. ${ }^{4,7-14}$ However, a particular feature of the FHS as delivered in this study could have contributed to confound the effect of SC on participants' outcomes. The family physicians who were part of the two FHS teams (with and without SC) had all completed their Family Medicine training at the same institution (FMRP University Hospital). As mentioned previously, this medical residency program in includes academic seminars and practical internships designed to train physicians in the prevention and management of MD. This specialized

Table 4 Comparison of the severity of pooled mental disorder (MD) categories among the three areas

\begin{tabular}{|c|c|c|c|c|c|}
\hline \multirow[b]{2}{*}{ Diagnosis } & \multicolumn{3}{|c|}{ Areas } & \multirow[b]{2}{*}{$\mathrm{F}$} & \multirow[b]{2}{*}{ p-value (ANOVA) } \\
\hline & FHS with SC & FHS without SC & $\mathrm{TC}$ & & \\
\hline \multicolumn{6}{|c|}{ Depressive disorders } \\
\hline MINI-Tracking & $1.63(0.78)$ & $1.45(0.66)$ & $1.78(0.65)$ & 2.379 & $0.097 *$ \\
\hline PHQ-9 & $11.63(6.23)$ & $9.92(5.28)$ & $12.3(7.30)$ & 1.567 & 0.213 \\
\hline \multicolumn{6}{|l|}{ Anxiety disorders } \\
\hline MINI-Tracking & $1.62(0.74)$ & $1.44(0.78)$ & $1.57(0.76)$ & 0.594 & 0.553 \\
\hline GAD-7 & $10.16(5.35)$ & $7.85(4.86)$ & $9.19(5.33)$ & 2.052 & 0.133 \\
\hline \multicolumn{6}{|c|}{ Alcohol abuse/dependence } \\
\hline MINI-Tracking & $1.98(1.31)$ & $1.10(0.40)$ & $1.49(0.89)$ & 1.052 & 0.377 \\
\hline AUDIT & $22.0(12.3)$ & $18.40(5.69)$ & $17.88(4.12)$ & 0.475 & 0.631 \\
\hline \multicolumn{6}{|c|}{ Psychotic syndrome } \\
\hline MINI-Tracking & $0.88(2.11)$ & $0.48(0.73)$ & $0.59(0.61)$ & 0.284 & 0.754 \\
\hline BPRS & $9.72(5.23)$ & $7.65(4.71)$ & 11.59 (10.37) & 1.817 & 0.169 \\
\hline
\end{tabular}

Data presented as mean (standard deviation), unless otherwise specified.

ANOVA = analysis of variance; AUDIT = Alcohol Use Disorder Identification Test; BPRS = Brief Psychiatric Rating Scale; FHS = Family Health Strategy; GAD-7 = Generalized Anxiety Disorder Scale-7; MINI-Tracking = Mini International Neuropsychiatric Interview - Tracking, validated in Portuguese (very similar to the MINI, with the exception that it offers a five-degree scale of severity instead of yes and no answers); PHQ-9=

Patient Health Questionnaire-9; SC = shared mental health care.

* Trend toward significance $(p<0.10)$ 
training may have overshadowed the influence of mentalhealth SC on the FHS, and affected the generalization of our results.

In our study, MD diagnoses were grouped into four categories (depressive disorders, anxiety disorders, alcohol abuse/dependence, and psychotic syndrome) in order to assess differences in the severity of MD symptoms. Statistically significant differences were not observed across the three areas regarding severity of symptoms in these four groups, as assessed with disorder-specific instruments (PHQ-9, GAD-7, AUDIT, and BPRS). However, there was a trend toward greater symptom severity $(p=0.06)$ in the depressive disorders category in the area covered by TC compared to the areas covered by FHS.

As this study used a cross-sectional design, the selected samples may not have been large enough to express possible differences in the severity of MD symptoms, except for the statistical tendency in the case of depressive disorders. Depressive disorders were the most prevalent MDs among the selected participants. The percentage of any MD evaluated with the MINI interview was $40.5 \%$, with depressive disorders accounting for $29.2 \%$ (Table 2). These percentages were higher than those described in previous epidemiological studies conducted with large samples and household interviewing in the city of São Paulo. ${ }^{28}$ In a sample of 5,037 adults, the authors of that study detected an overall 12-month MD prevalence of $29.6 \%$, including anxiety, mood and impulse control, and substance use disorders. The higher percentage of MD in the present study may be related to the high proportion of patients receiving $\mathrm{PHC}$ care; the prevalence of $\mathrm{MD}$ in primary-care settings is known to be higher than in the general population. Moreover, these discrepancies may result from methodological differences between the two studies, including in sampling procedures (drawing one respondent per household vs. all those who agreed to participate in each house), diagnostic instruments (Composite International Diagnostic Interview [CIDI] vs. MINI), and interviewers (professional interviewers from an opinion research company vs. mental health professionals). However, the results of the two studies converged in the finding that depressive and anxiety disorders were the most frequent MDs. The higher percentage of depressive disorders in the present study may have contributed to the differences seen in their severity between the TC and $\mathrm{FHS}$ areas.

In conclusion, the main finding of this study was that delivery of care via the FHS was associated with a significantly lower percentage of MDs. An important feature of the FHS model assessed herein was that the family physicians in charge of care had all received intense training in mental health during their Family and Community Medicine residency program. The presence of SC had no influence on the prevalence of MD, suggesting that the special characteristic of the FHS teams working in the sampled areas may have obscured the effect of SC. In this sense, these results should not be generalized, since not all FHS teams in Brazil are staffed by family physicians, nor do all family physicians in the country receive mental-health training as the doctors in this study did. These findings should encourage health managers to increase FHS coverage and broaden training of family physicians in mental health.

\section{Acknowledgements}

AWZ is a Conselho Nacional de Desenvolvimento Científico e Tecnológico (CNPq) research fellow. This study received a grant from Fundação de Amparo à Pesquisa do Estado de São Paulo (FAPESP) (no. 388 2011/50740-5).

\section{Disclosure}

The authors report no conflicts of interest.

\section{References}

1 World Health Organization (WHO), United Nations Children's Fund (UNICEF). A vision for primary health care in the 21 st century: towards universal health coverage and the sustainable development goals. Geneva: WHO and UNICEF; 2018.

2 Paim J, Travassos C, Almeida C, Bahia L, Macinko J. The Brazilian health system: history, advances, and challenges. Lancet. 2011;377: 1778-97.

3 Brasil, Ministério da Saúde, Departamento de Atenção Básica [Internet]. [cited 2019 Mar 31]. https://www.saude.gov.br/acoes-eprogramas/saude-da-familia

4 Gillies D, Buykx P, Parker AG, Hetrick SE. Consultation liaison in primary care for people with mental disorders. Cochrane Database Syst Rev. 2015;9:CD007193.

5 Bonadiman CS, de Azeredo Passos VM, Mooney M, Naghavi M, Melo AP. The burden of disease attributable to mental and substance use disorders in Brazil: global burden of disease study, 1990 and 2015. Rev Bras Epidemiol. 2017;20(Suppl 1):191-204.

6 World Health Organization (WHO), World Health Organization and World Organization of Family Doctors (WONCA). Integrating mental health into primary care: a global perspective. Geneva: WHO Library Cataloguing-in-Publication Data; 2008.

7 Archer J, Bower P, Gilbody S, Lovell K, Richards D, Gask L, et al. Collaborative care for depression and anxiety problems. Cochrane Database Syst Rev. 2012;10:CD006525.

8 Moscovici L, de Azevedo-Marques JM, Zuardi A. Integrated mental healthcare: outcomes from Brazilian primary care. Eur J Pers Cent Healthc. 2016;4:669-74.

9 Foy R, Hempel S, Rubenstein L, Suttorp M, Seelig M, Shanman R, et al. Meta-analysis: effect of interactive communication between collaborating primary care physicians and specialists. Ann Intern Med. 2010;152:247-58.

10 Sepúlveda R, Zitko P, Ramírez J, Markkula N, Alvarado R. Primary care consultation liaison and the rate of psychiatric hospitalizations: a countrywide study in Chile. Rev Panam Salud Publica. 2018;42: e138.

11 Baxter S, Johnson M, Chambers D, Sutton A, Elizabeth G, Booth A The effects of integrated care: a systematic review of UK and international evidence. BMC Health Serv Res. 2018;18:350.

12 Richards DA, Hill JJ, Gask L, Lovell K, Chew-Graham C, Bower P et al. Clinical effectiveness of collaborative care for depression in UK primary care (CADET): cluster randomised controlled trial. BMJ. 2013;347:f4913.

13 Kates N, Mach M. Chronic disease management for depression in primary care: a summary of the current literature and implications for practice. Can J Psychiatry. 2007;52:77-85.

14 Gonçalves DA, Mari JJ, Bower P, Gask L, Dowrick C, Tófoli LF, et al. Brazilian multicentre study of common mental disorders in primary care: rates and related social and demographic factors. Cad Saude Publica. 2014;30:623-32.

15 Del-Ben CM, Shuhama R, Loureiro CM, Ragazzi TC, Zanatta DP, Tenan $\mathrm{SH}$, et al. Urbanicity and risk of first-episode psychosis: incidence study in Brazil. Br J Psychiatry. 2019;215:726-9.

16 Moscovici L, de Azevedo-Marques JM, Bolsoni LM, Rodrigues-Junior $A L$, Zuardi AW. Impact of different approaches of primary care mental 
health on the prevalence of mental disorders. Prim Health Care Res Dev. 2018;19:256-63.

17 Sheehan DV, Lecrubier Y, Sheehan KH, Amorim P, Janavs J, Weiller E, et al. The Mini-International Neuropsychiatric Interview (M.I.N.I.): the development and validation of a structured diagnostic psychiatric interview for DSM-IV and ICD-10. J Clin Psychiatry. 1998;59(Suppl 20): 22-33;quiz 34-57.

18 Amorim P. Mini International Neuropsychiatric Interview (MINI): validação de entrevista breve para diagnóstico de transtornos mentais. Braz J Psychiatry. 2000;22:106-15.

19 de Azevedo Marques JM, Zuardi AW. Validity and applicability of the Mini International Neuropsychiatric Interview administered by family medicine residents in primary health care in Brazil. Gen Hosp Psychiatry. 2008;30:303-10.

20 Moscovici L. Avaliação de propriedades psicométricas e de resultados da aplicação da versão brasileira do 'Mini International Neuropsychiatric Interview - TRACKING' em usuários da Estratégia de Saúde da Família acompanhados com ou sem cuidado colaborativo em saúde mental [thesis]. Ribeirão Preto: Universidade de São Paulo; 2013.

21 de Lima Osório F, Mendes AV, Crippa JA, Loureiro SR. Study of the discriminative validity of the PHQ-9 and PHQ-2 in a sample of Brazilian women in the context of primary health care. Perspect Psychiatr Care. 2009;45:216-27.
22 Kroenke K, Spitzer RL, Williams JB. The PHQ-9: validity of a brief depression severity measure. J Gen Intern Med. 2001;16:606-13.

23 Kroenke K, Spitzer RL, Williams JB, Monahan PO, Löwe B. Anxiety disorders in primary care: prevalence, impairment, comorbidity, and detection. Ann Intern Med. 2007;146:317-25.

24 Löwe B, Decker O, Müller S, Brähler E, Schellberg D, Herzog W, et al. Validation and standardization of the Generalized Anxiety Disorder Screener (GAD-7) in the general population. Med Care. 2008;46:266-74.

25 Figlie NB, Pillon SC, Laranjeira RR, Dunn J. AUDIT identifica a necessidade de interconsulta específica para dependentes de álcool no hospital geral? J Bras Psiquiatr. 1997;11:589-93.

26 Meneses-Gaya C, Zuardi AW, Loureiro SR, Hallak JE, Trzesniak C, de Azevedo Marques JM, et al. Is the full version of the AUDIT really necessary? Study of the validity and internal construct of its abbreviated versions. Alcohol Clin Exp Res. 2010;34:1417-24.

27 Zuardi AW, Loureiro SR, Rodrigues CRC, Correa AJ, Glock SS. Estudo da estrutura fatorial, fidedignidade e validade da tradução e adaptação para o português da Escala de Avaliação Psiquiátrica Breve (BPRS) modificada. Rev ABP-APAL. 1994;16:63-8.

28 Andrade LH, Wang YP, Andreoni S, Silveira CM, Alexandrino-Silva $\mathrm{C}$, Siu ER, et al. Mental disorders in megacities: findings from the São Paulo megacity mental health survey, Brazil. PLoS One. 2012;7: e31879. 